\title{
PHYSICAL THERAPY IN ADULTS WITH RESPIRATORY DISORDERS: WHERE ARE WE?
}

\author{
GosSELINK R \\ Respiratory Rehabilitation and Respiratory Division, Faculty of Kinesiology and Rehabilitation Sciences, University \\ Hospitals Leuven, Katholieke Universiteit Leuven, Belgium \\ Correspondence to: Rik Gosselink, Ph.D., P.T., Professor in Rehabilitation Sciences, Respiratory Rehabilitation and \\ Respiratory Division, University Hospitals Leuven, Faculty of Kinesiology and Rehabilitation Sciences, Katholieke \\ Universiteit Leuven, B-3000, Belgium, e-mail: rik.gosselink@faber.kuleuven.be
}

Received: 17/07/2006 - Revised: 14/08/2006 - Accepted: 28/08/2006

\begin{abstract}
Introduction: Physical therapy is involved in the non-medical treatment of patients with acute and chronic respiratory diseases, including obstructive and restrictive pulmonary diseases, patients with neuromuscular disorders, patients admitted for major surgery and patients with critical illness in intensive care. Physical therapy contributes towards assessing and treating various aspects of respiratory disorders such as airflow obstruction, mucus retention, alterations in ventilatory pump function, dyspnea, impaired exercise performance and quality of life. Conclusion: Exercise training, peripheral and respiratory muscle training, airway clearance techniques and lung expansion in spontaneous breathing patients (lung expansion maneuvers, huffing and assisted coughing) and in mechanically ventilated patients (bagsqueezing), and breathing retraining (pursed lips breathing, active expiration) have been shown effective in selected patients with disorders affecting the respiratory system. Assessment of patients is critical to identify patient characteristics that allow appropriate selection of treatment modalities providing optimal effectiveness and efficacy.
\end{abstract}

Key words: breathing retraining, effectiveness of respiratory techniques, functional capacity.

\section{RESUMO}

\section{Fisioterapia em Adultos com Distúrbios Respiratórios: Onde Estamos?}

Introdução: Fisioterapia envolve o tratamento não-médico de pacientes com doenças respiratórias agudas e crônicas, incluindo doenças pulmonares obstrutivas e restritivas; pacientes com doenças neuromusculares; pacientes submetidos a grandes cirurgias e pacientes com doenças graves, em terapia intensiva. A fisioterapia contribui para a avaliação e para o tratamento de vários aspectos das doenças respiratórias, tais como obstrução do fluxo aéreo; retenção de secreção; alterações na função ventilatória; dispnéia, mau condicionamento físico; além de contribuir para a melhora da qualidade de vida. Conclusão: Esta revisão discute a eficácia do treinamento físico, do treinamento periférico e muscular, de técnicas de limpeza das vias aéreas, e a função respiratória em relação a uma variedade de condições que afetam o sistema respiratório.

Palavras-chave: retreinamento respiratório, efetividade de técnicas respiratórias, capacidade funcional.

\section{INTRODUCTION}

Physical therapy is relevant to the treatment of patients with acute and chronic lung disease, but is also effective in patients with advanced neuromuscular disorders, in patients admitted for major surgery and patients with critical illness in intensive care units. Physical therapy contributes towards assessing and treating various aspects of respiratory disorders such as airflow obstruction, mucus retention, alterations in ventilatory pump function, dyspnea, impaired exercise performance and quality of life. Since lack of compliance with treatment is a well-known problem in prescribing techniques for airway clearance and maintaining the effects from exercise training following rehabilitation, physical therapy also includes patient education. This overview discusses airway clearance techniques, breathing retraining, exercise training and peripheral and respiratory muscle training, in relation to a variety of conditions affecting the respiratory system. 


\section{DECONDITIONING: EXERCISE TRAINING AND PERIPHERAL MUSCLE TRAINING}

Impaired exercise tolerance is a common finding in patients with respiratory disease. However, reduced exercise capacity shows only a weak relationship with impairment of lung function. Other factors, such as peripheral and respiratory muscle weakness and deconditioning, are now recognized as important contributors towards reduced exercise tolerance ${ }^{1,2}$. Randomized controlled studies on the efficacy of pulmonary rehabilitation have reported significant improvements in maximal exercise capacity, walking distance and endurance capacity following pulmonary rehabilitation. In addition, improved quality of life and reduced symptoms have been observed ${ }^{3,4}$. Although these programs are comprehensive, most authors consider exercise training to be a mandatory part of such programs. Endurance training involves a larger muscle mass working at moderate intensity for a longer period of time. For patients with more advanced disease, reducing the impact on the cardiopulmonary system, by shortening the exercise duration and/or reducing active muscle mass is indicated. Indeed, interval training and resistance muscle training (Figure 1) are appropriate and effective alternatives to endurance exercise training ${ }^{5,6}$. Randomized controlled trials on chronic obstructive pulmonary disease (COPD) patients have found that weight-lifting resulted in significant increases in peripheral muscle performance, endurance exercise capacity and quality of life ${ }^{7}$. In COPD patients with peripheral muscle weakness, strength training has been shown to be equally effective as endurance training on exercise capacity and quality of life ${ }^{6}$. The combination of strength and endurance training has improved peripheral muscle strength, exercise performance and quality of life in COPD patients with muscle weakness, compared with either endurance training or strength training alone ${ }^{8}$. Recently, neuromuscular stimulation of lower limb muscles in patients with severe COPD has been shown to improve muscle strength, exercise performance and quality of life ${ }^{9}$.

Clinical conditions associated with severe deconditioning, such as critical illness and burn injuries need input from physiotherapists, to maintain or restore the patient's ability to be "upright and moving" and thus shorten bed rest ${ }^{10}$. Mobilization enhances oxygen transport, muscle function, joint mobility and coordination of movement. Prevention of muscle atrophy is best achieved with active muscle contractions, but critically ill patients are often unable to perform voluntary contractions. Under these conditions, active or passive cycling (Figure 2) or passive muscle stretching has been shown to prevent muscle fiber atrophy and protein loss, in comparison with twice-a-day passive stretching of less than 5 minutes per session ${ }^{11}$. Moreover, electrical stimulation of the quadriceps (Figure 3) not only gives rise to active limb mobilization but also enhances muscle strength and decreases the number of days needed to transfer from

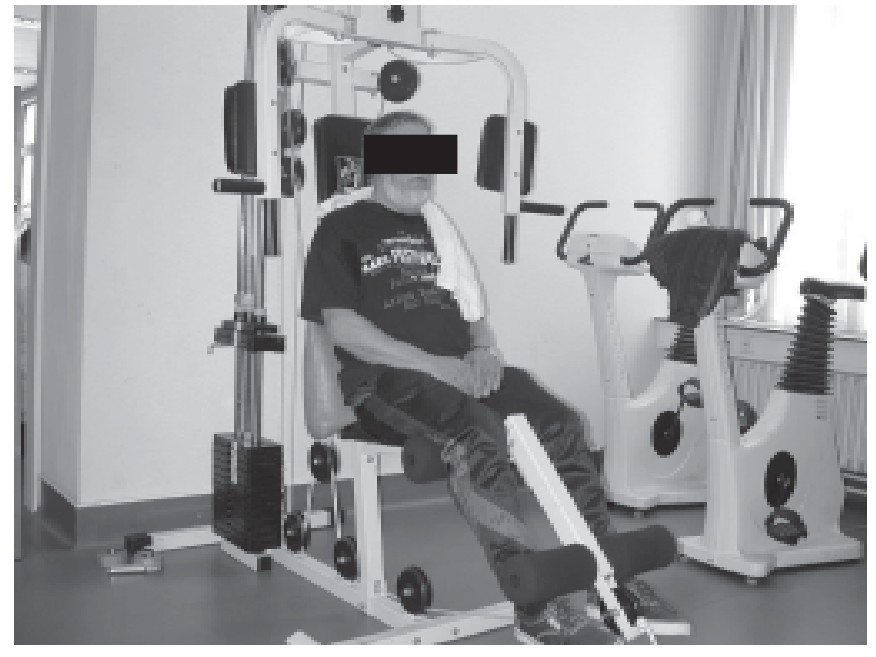

Figure 1. Resistance muscle training for lower limbs in a patient with COPD.

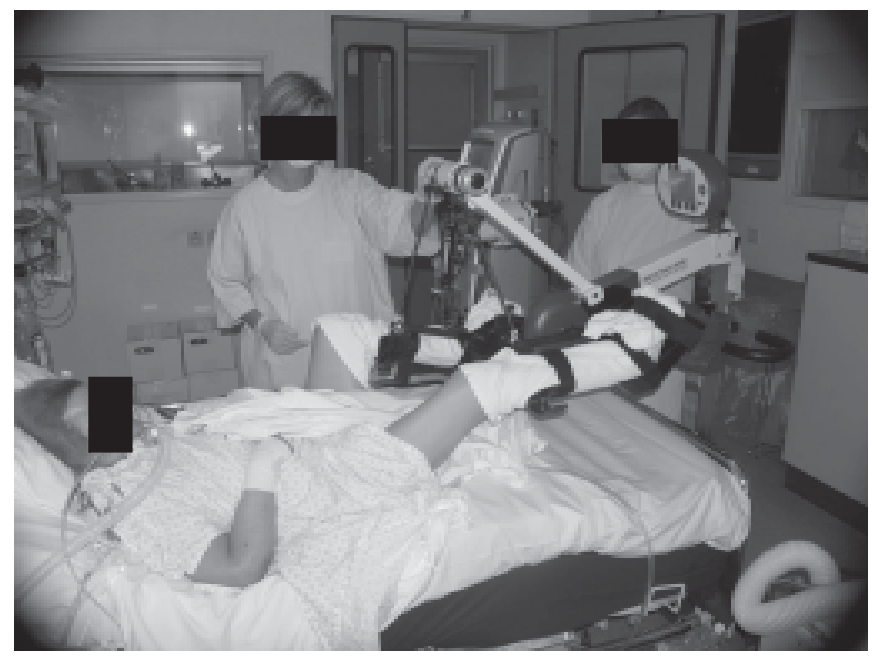

Figure 2. Device for active and passive cycling in a bedridden patient in intensive care (Motomed Letto, RECK Germany).

bed to chair ${ }^{12}$. Recent studies have underpinned the need for exercise training after a period of critical illness, to enhance functional capacity ${ }^{13}$.

\section{DYSPNEAAND RESPIRATORY PUMP DYSFUNCTION}

Dyspnea is an important and debilitating symptom in patients with $\mathrm{COPD}^{14}$. Several pathophysiological factors known to contribute towards dyspnea include: (i) increased intrinsic mechanical loading of the inspiratory muscles, (ii) increased mechanical restriction of the chest wall, (iii) functional inspiratory muscle weakness, (iiii) increased ventilatory demand relative to capacity, (iv) gas exchange abnormalities, (v) dynamic airway compression, or (vi) 
cardiovascular effects ${ }^{15}$. Dyspnea relief is an important aim in the treatment of COPD, which is an only partially reversible disease. Among the treatment methods commonly applied (such as bronchodilator therapy, exercise training and oxygen therapy), breathing techniques are also applied to alleviate symptoms and improve respiratory physiology.
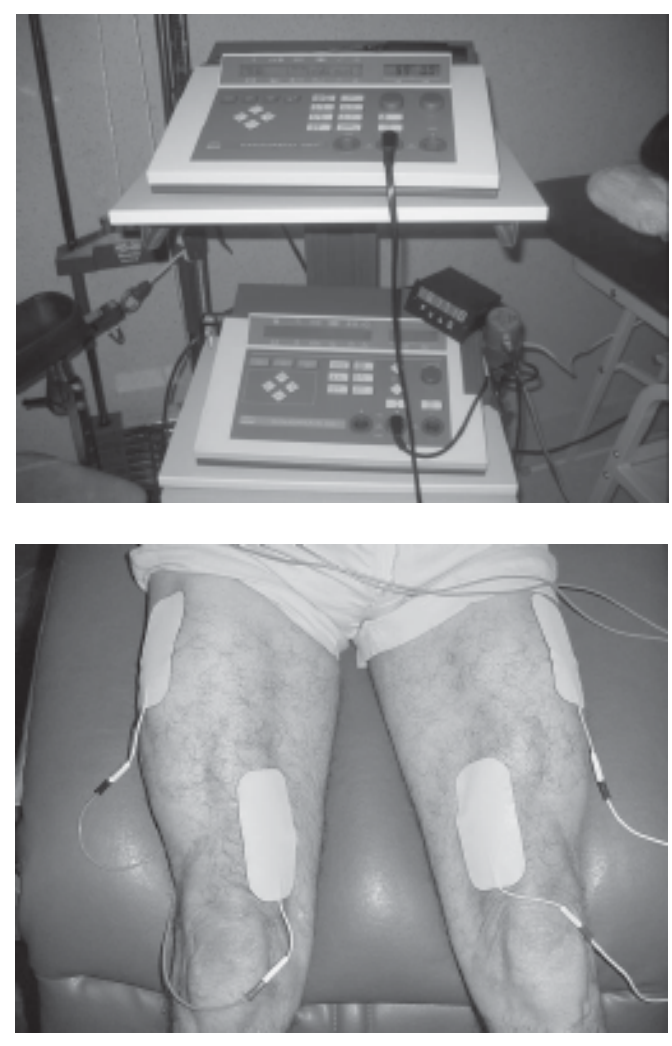

Figure 3. Neuromuscular stimulation of the quadriceps femoris muscle.

"Breathing exercise" is an all-embracing term for a range of exercises such as active expiration, slow and deep breathing, pursed lips breathing, relaxation therapy, body positions such as forward leaning, inspiratory and expiratory muscle training, and diaphragmatic breathing. The aims of these exercises vary considerably and include the improvement of (regional) ventilation and gas exchange, reduction of dynamic hyperinflation, improvement of respiratory muscle function, reduction of dyspnea and improvement of exercise tolerance and quality of life ${ }^{16}$.

\section{Breathing retraining to reduce dynamic hyperinflation of the rib cage}

The idea of decreasing the dynamic hyperinflation of the rib cage is based on the assumption that this intervention will decrease the elastic work of breathing and allow the inspiratory muscles to work over a more advantageous part of their length-tension relationship. There are several treatment strategies that aim to reduce chest wall hyperinflation.

\section{Relaxation exercises}

The rationale for relaxation exercises arises from the observation that slowing down the respiratory rate will allow more time for expiration. Renfoe ${ }^{17}$ showed in COPD patients that progressive relaxation resulted in an immediate decrease in heart rate, respiratory rate, anxiety and dyspnea scores in comparison with a control group, but only the respiratory rate dropped significantly over time. Gift et al. ${ }^{18}$ observed similar improvements in a randomized controlled trial with relaxation using audio tapes, in comparison with a control group. Significantly larger reductions in breathing rate, anxiety and dyspnea than in the control group were found. Kolaczkowski et al. ${ }^{19}$ observed that the combination of relaxation exercises and manual compression of the thorax improved the excursion of the thorax and oxygen saturation significantly. A positive trend towards symptom reduction is apparent in applying relaxation exercises.

\section{Pursed lips breathing}

Pursed lips breathing aims to improve expiration both by the active and prolonged expiration through the half-opened lips and by preventing airway collapse. Compared with spontaneous breathing, pursed lips breathing reduces the respiratory rate, dyspnea and $\mathrm{PaCO}_{2}$, and improves tidal volume and oxygen saturation under resting conditions ${ }^{20,21}$. However, its application during treadmill exercise has not been found to improve blood gases ${ }^{22}$. Recently Garrod et al. observed that pursed lips breathing during a six-minute walking test resulted in a lower respiratory rate after the walking test, in comparison with natural breathing during the walking test ${ }^{23}$. Breslin $^{20}$ observed an increase in rib-cage and accessory muscle recruitment during pursed lip breathing, over the entire breathing cycle, while the tension-time index of the diaphragmatic contraction decreased. These changes might have contributed towards the decrease in dyspnea sensation.

Some COPD patients use the technique instinctively, while other patients do not. The changes in minute ventilation and gas exchange have not been found to be significantly related to the patients who reported subjective improvement in the sensation of dyspnea. These "symptom benefit patients" had a more markedly increased tidal volume and decreased breathing frequency ${ }^{22}$. On the other hand, there are other reports of reduced elastic recoil pressure in symptom benefit patients ${ }^{21}$.

In conclusion, pursed lips breathing is found to be effective in improving gas exchange and reducing dyspnea. COPD patients who do not spontaneously adopt pursed lips breathing show variable responses. Patients with loss of elastic recoil pressure seem to benefit more from practicing this technique during exertion and episodes of dyspnea. 


\section{Breathing retraining to improve respiratory muscle function}

Reduced endurance and strength of the inspiratory muscles are frequently observed in chronic lung disease and neuromuscular disorders and contribute towards dyspnea and exercise limitation, and probably towards respiratory failure. Improvement of respiratory muscle function has the aim of reducing the relative load on the muscles (the ratio between the actual pressure and the maximal pressure; PI/ PImax) and hence may contribute towards reducing dyspnea and increasing the maximal sustained ventilatory capacity. This might also imply improvement in exercise capacity among patients with ventilatory limitation during exercise. Breathing retraining and body positions have the aim of improving the length-tension relationship or geometry of the respiratory muscles (in particular the diaphragm), or increasing the strength and endurance of the inspiratory muscles. According to the length-tension relationship, the output from the muscle increases when operating at a greater length, for the same neural input. At the same time, the efficacy of the contraction in moving the rib cage improves. Moreover, the piston-like movement of the diaphragm increases and enhances the lung volume changes.

\section{Contraction of the abdominal muscles during expiration}

Contraction of the abdominal muscles during expiration lengthens the diaphragm, thus allowing it to operate close to its optimal length. In addition, active expiration will increase the elastic recoil pressure of the diaphragm and rib cage. The release of this pressure after relaxation of the expiratory muscles will assist the next inspiration. In healthy subjects, this mechanism is brought into play only with increased ventilation. However, in patients with severe COPD, contraction of abdominal muscles invariably becomes linked to resting breathing ${ }^{24}$. Active expiration increases the transdiaphragmatic pressure (Pdi) and PImax. The additional effects of active expiration on exercise training among patients with severe COPD were studied by Casciari et $\mathrm{al}^{25}$. They observed a significant increase in maximum oxygen uptake during a bicycle ergometer test, following a period of additional breathing retraining as part of a training program on a treadmill, in comparison with the treadmill program without breathing retraining.

Although active expiration seems to improve inspiratory muscle function and is commonly observed in resting breathing and during exercise in COPD patients, the significance of abdominal muscle activity remains poorly understood ${ }^{24}$.

\section{Body position}

Relief of dyspnea is often experienced by patients in different body positions. Forward leaning has been shown to be very effective in $\mathrm{COPD}^{26}$ and is probably the body position most adopted by patients with lung disease (Figure 4). The effect of this position seems to be unrelated to the severity of airway obstruction, changes in minute ventilation or improved oxygenation ${ }^{26}$. Hyperinflation and paradoxical abdominal movement have indeed been related to dyspnea relief in the forward leaning position ${ }^{26}$. Alternatively, forward leaning has been associated with significantly reduced electromyographic (EMG) activity in the scalene and sternomastoid muscles, increased transdiaphragmatic pressure and significantly improved thoracoabdominal movements ${ }^{26}$. From these studies, it was concluded that the subjective improvement in dyspnea among patients with COPD was the result of the more favorable position of the diaphragm on its length-tension curve. In addition, forward leaning with arm support allows accessory muscles (pectoralis minor and major) to contribute significantly towards rib cage elevation. Banzett showed in healthy subjects that this position enhanced ventilatory capacity ${ }^{27}$. The same holds for the forward leaning position with head support, which allows the accessory neck muscles to assist inspiration.

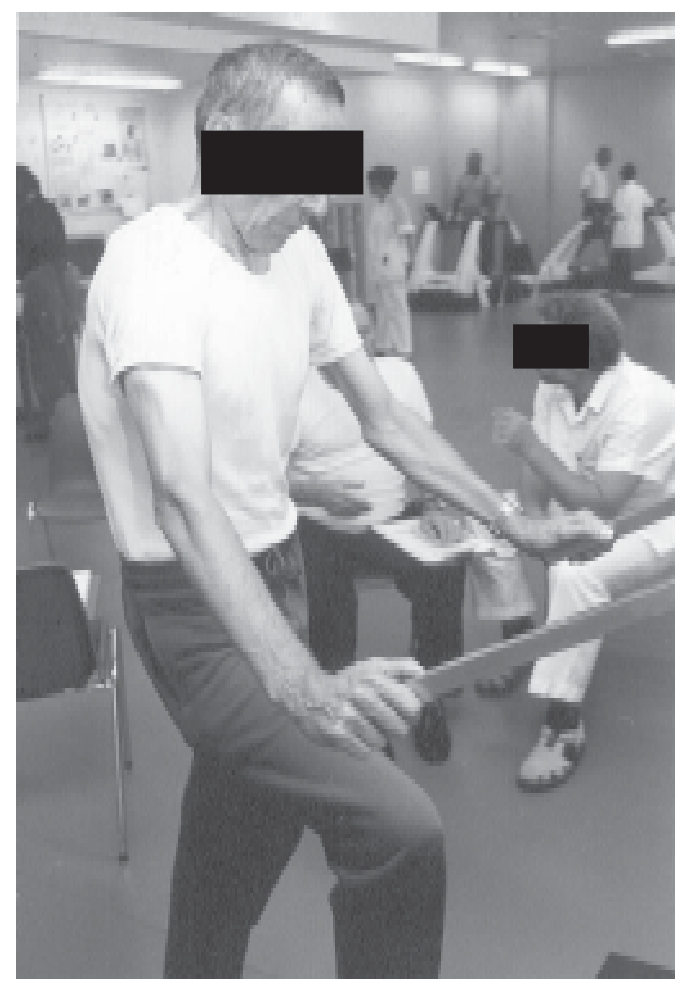

Figure 4. Forward leaning position allowing accessory muscle recruitment and dyspnea relief.

\section{Abdominal belt}

The "abdominal belt" was developed as an aid to support diaphragmatic function. Early studies reported on its use on patients with emphysema, but it has only been successfully used on patients with spinal cord injury, for whom it improves vital capacity ${ }^{28}$. However, increased expiratory flow and expiratory pressures during abdominal 
strapping have not been consistently observed in such patients ${ }^{29}$.

\section{Respiratory muscle training}

Recent studies on patients with COPD have shown natural adaptations of the diaphragm at cellular level (increased proportion of type I fibers) and subcellular level (shortened sarcomeres and increased mitochondria concentration), which contributes towards greater fatigue resistance and better functional muscle behavior ${ }^{30}$. Despite these cellular adaptations, both functional inspiratory muscle strength and inspiratory muscle endurance are compromised in COPD cases. Inspiratory muscle training may further enhance these spontaneous adaptations.

Three types of training are practiced at the present time: inspiratory resistive training (IRT), threshold loading (ITL) and normocapnic hyperpnea (NCH). During NCH the patient is asked to ventilate maximally for 15-20 minutes (Figure 5).

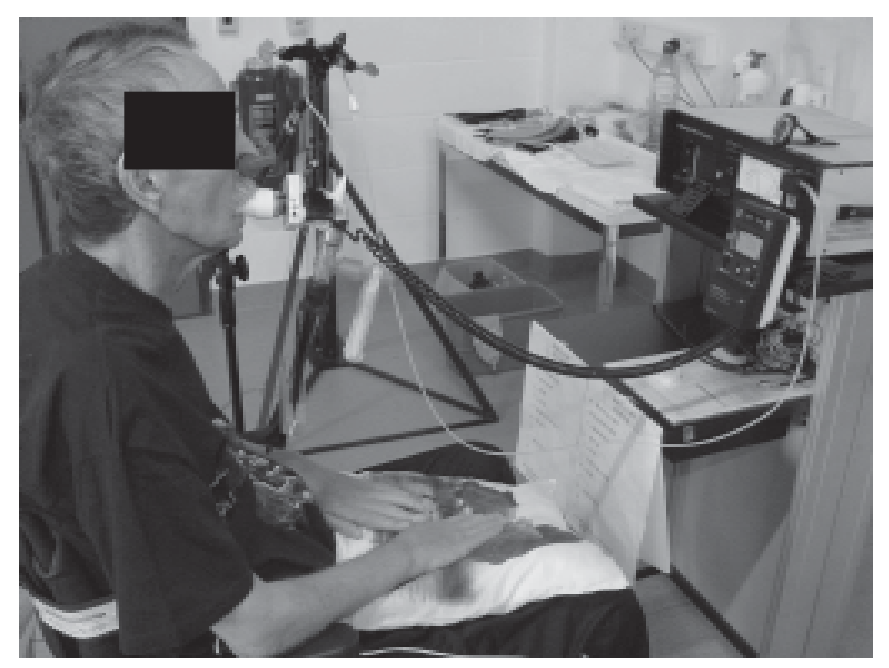

Figure 5. Normocapnic hyperpnea training in a patient with spinal cord injury.

In a randomized controlled trial, NCH was shown to enhance respiratory muscle endurance and exercise capacity, as well as quality of life, in COPD patients ${ }^{31}$. During inspiratory resistive breathing, the patient inspires through a mouthpiece and adapter with an adjustable diameter or "threshold loading" (Figure 6). Most studies have observed that breathing against an inspiratory load (at least 30\% PImax) increased maximal inspiratory pressure and endurance capacity of the inspiratory muscles (see overview ${ }^{32}$ ). A recent study on COPD patients has shown significant increases in the proportion of type I fibers and the size of type II fibers in the external intercostals following IMT $^{33}$. Dyspnea ${ }^{34}$ and nocturnal desaturation time ${ }^{35}$ also decreased, while exercise performance tended to improve $^{32}$. Inspiratory muscle training in addition to exercise training has been shown to improve exercise capacity more than does exercise training alone ${ }^{36,37}$. The additional effect of IMT on exercise performance seems to be related to the presence of inspiratory muscle weakness ${ }^{32}$. At present there are no data to support resistive or threshold loading as the training method of choice. Threshold loading enhances the velocity of inspiratory muscle shortening ${ }^{38}$. This might be an important additional effect, as this shortens inspiratory time and increases the exhalation and relaxation time.

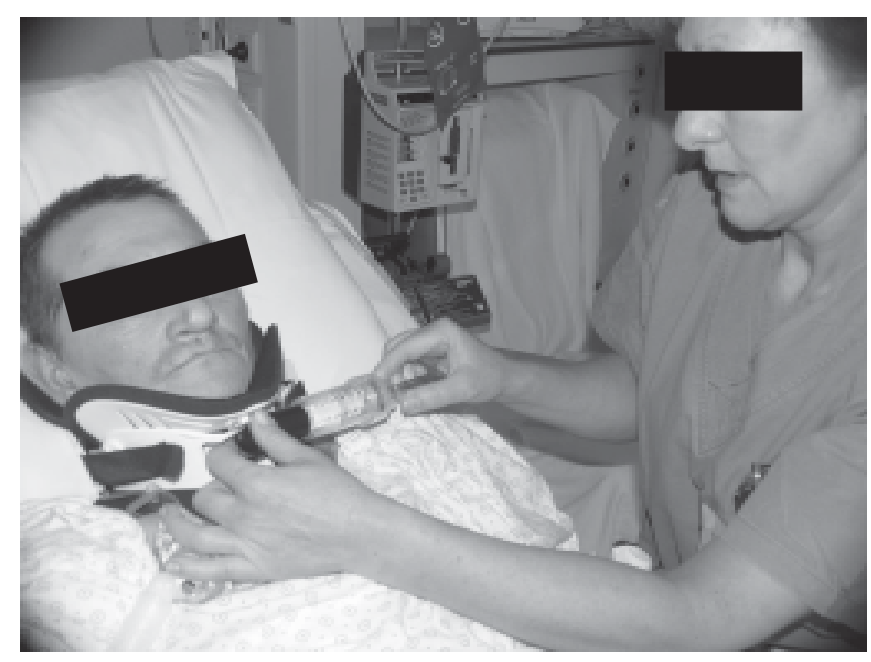

Figure 6. Respiratory muscle resistive training with threshold loading in a patient being weaned off mechanical ventilation.

It is concluded that, in COPD cases, well-controlled inspiratory muscle training improves inspiratory muscle function, thereby resulting in additional decreases in dyspnea and nocturnal desaturation time and potential improvement in exercise capacity, in patients with inspiratory muscle weakness. Training intensity should be at least 30\% of the maximal inspiratory pressure for 30 minutes per day.

In quadriplegic patients, respiratory muscle training has also been shown to enhance inspiratory muscle function, pulmonary function and dyspnea ${ }^{39,40}$, but a recent systematic review could not confirm this ${ }^{41}$. In patients with neuromuscular disease (NMD), respiratory muscle dysfunction is more complex and dependent on the precise disease and its stage. It seems that NMD patients for whom more than $25 \%$ of the predicted pulmonary function still remains are still trainable ${ }^{42}$. Although inspiratory muscle function is commonly affected in these diseases, expiratory muscle function is often more impaired in quadriplegia and multiple sclerosis. Expiratory muscle training has also been shown to be beneficial in the latter condition ${ }^{43}$. Over the long term, the progressive nature of most neuromuscular diseases affecting the primary function of the muscle probably impedes the beneficial effects of training. 
Finally, respiratory muscle weakness is a frequent cause of weaning failure. Uncontrolled trials have suggested that inspiratory muscle training during the weaning period could facilitate the weaning process ${ }^{44,45}$. Biofeedback of breathing patterns to such patients can also enhance the weaning process for patients receiving long-term mechanical ventilation $^{46}$.

\section{Breathing retraining to optimize thoracoabdominal movements}

Alterations in chest wall motion are common in patients with asthma and COPD. Several studies have described increased rib cage contribution towards chest wall motion and/or asynchrony between rib cage and abdominal motion in these patients ${ }^{47,48}$. The mechanisms underlying these alterations have not been fully elucidated, but appear to be related to the degree of airflow obstruction, hyperinflation of the rib cage, changes in diaphragmatic function and increased contribution of accessory inspiratory muscles towards chest wall motion. Indeed, increased firing frequency of single motor units of the scalene and parasternal muscles 49, and also of the diaphragm ${ }^{50,51}$, have been observed in COPD patients compared with age-matched control subjects. The activity of accessory muscles has been positively associated with the sensation of dyspnea, whereas diaphragm activity has been negatively related to this sensation ${ }^{52}$. Consequently, diaphragmatic breathing, or slow and deep breathing, are commonly applied in physical therapy practice, in attempts to correct abnormal chest wall motion and decrease the breathing work, accessory muscle activity and dyspnea.

\section{Diaphragmatic breathing}

During diaphragmatic breathing, the patient is told to move the abdominal wall predominantly during inspiration and to reduce upper rib cage motion. All studies have shown that, during diaphragmatic breathing, COPD patients are voluntarily able to change their breathing patterns to more abdominal movement and less thoracic excursion ${ }^{53,54}$. However, diaphragmatic breathing may be accompanied by increased asynchronous and paradoxical breathing movements, while no permanent changes in breathing pattern are observed ${ }^{53,54}$. Although abdominal and thoracic movement clearly changes, no changes in ventilation distribution has been observed ${ }^{54}$. In addition, dyspnea has been found to worsen during diaphragmatic breathing, while increased breathing work, enhanced oxygen cost in breathing and reduced mechanical efficiency of breathing have been found in patients with severe COPD ${ }^{55}$.

In conclusion, there is no evidence from controlled studies to support the use of diaphragmatic breathing in COPD patients.

\section{Slow and deep breathing}

Since, for a given minute ventilation, alveolar ventilation improves when breathing at a slower rate and higher tidal volume, this type of breathing is encouraged for patients with impaired alveolar ventilation. Several authors have reported a significant drop in respiratory frequency, and significant rise in tidal volume and $\mathrm{PaO}_{2}$ during imposed low frequency breathing at rest in patients with COPD (see pursed lips breathing). Slow and deep breathing retraining as part of pulmonary rehabilitation during exercise training may add to more efficient breathing during exercise and hence reduce the ventilatory demand and dyspnea ${ }^{56}$.

In summary, slow and deep breathing improves breathing efficiency and oxygen saturation at rest. A similar tendency has been observed during exercise, but needs further research.

\section{IMPAIRED AIRWAY CLEARANCE AND LUNG INFLATION}

Hypersecretion and impaired mucociliary transport are important pathophysiological features of obstructive lung diseases like cystic fibrosis and chronic bronchitis, as well as in patients with acute lung disease, i.e. atelectasis and pneumonia. Hypersecretion is associated with an increased rate of decline of pulmonary function and excess mortality in patients with $\mathrm{COPD}^{57}$. In patients with more advanced neuromuscular disease, mucus retention and pulmonary complications significantly contribute towards morbidity and mortality ${ }^{58}$. Although a cause-effect relationship has not been proven under these conditions, improvement of airway clearance is considered to be an important aim in treating such patients.

Pharmaceutical interventions and physical therapy are effective in enhancing mucus transport by improving the rheological properties of the mucus layer (thus stimulating ciliary action) or by using compensatory physical mechanisms such as gravity, two-phase gas-liquid interaction, vibration, oscillation or airway compression ${ }^{59,60}$. A meta-analysis on patients with cystic fibrosis ${ }^{61}$ concluded that the combined standard treatment of postural drainage, percussion and vibration resulted in significantly greater sputum expectoration than did no treatment. No differences were observed between standard treatment and other treatment methods. A Cochrane Library review on patients with COPD and bronchiectasis concluded that the combination of postural drainage, percussion and forced expiration improved the airway clearance but not pulmonary function ${ }^{62}$. Forced expiratory maneuvers (hawking and coughing) are considered to be the cornerstone of airway clearance techniques and thus an essential part in every combination of treatment methods. 


\section{Forced expiration Tecniques}

The idea behind therapeutic forced expiratory maneuvers is to enhance mucus transport through the interaction and energy transfer between the high airflow velocity and the mucus layer (two-phase gas-liquid interaction). The effectiveness of this transmission and hence of mucus transport depends on the thickness of the mucus layer and airflow velocity. A thicker mucus layer is easier to move, as more kinetic energy is transmitted to the mucus layer ${ }^{63}$. Hawking and coughing, and also (although to a lesser extent) ventilation at rest or during exercise, induce higher airflow velocities that equally effectively stimulate mucus transport from the central and intermediate lung zones ${ }^{64-66}$. However, in patients with airway instability (pulmonary emphysema), forced expiratory maneuvers may result in airway collapse and impair mucus transport. Indeed, manual chest wall compression during forced expiration has been found to decrease the peak cough flow rate in patients with severe $\mathrm{COPD}^{67}$. In contrast, in neuromuscular disease (NMD), the reduced expiratory muscle strength limits effective hawking and coughing. Manual assistance with chest wall compression enhances the peak cough flow rate in patients with neuromuscular disease without scoliosis, but has not been beneficial in patients with chest wall deformities ${ }^{67}$. In addition, deep lung insufflation increases maximum insufflation capacity and peak cough flow in patients with progressive neuromuscular disease ${ }^{67}$. Mechanical insufflation and exsufflation and manually assisted coughing are effective and safe for facilitating the clearance of airway secretions ${ }^{68}$. Glossopharyngeal breathing has been shown to increase vital capacity and expiratory flow rates and is a treatment option for patients with high spinal cord injury ${ }^{69}$.

\section{Exercise}

During exercise, increased ventilation and release of mediators in the airways may be effective in enhancing mucus transport $^{70}$. Indeed, increased mucus transport has been observed during exercise in healthy subjects and patients with chronic bronchitis ${ }^{71}$, but it has been found to be less effective than conventional physical therapy in patients with cystic fibrosis $^{72}$. During exercise combined with physical therapy, significantly more sputum volume has been found to be expectorated than during physical therapy alone ${ }^{73}$.

\section{Postural drainage and Body position}

During postural drainage, the major bronchi are positioned to allow gravitational forces to promote mucus transport to the central airways. Studies investigating the efficacy of postural drainage and using radioaerosol tracer assessment have not shown any additional improvement in mucus transport following postural drainage ${ }^{74}$ but, in patients with bronchiectasis and excessive mucus production, postural drainage alone enhanced mucus transport and expectoration ${ }^{75}$.
Body position has also been shown to affect oxygenation. This effect has not always been acknowledged in clinical care. In patients with unilateral lung disease, the lateral decubitus position with the unaffected side down generally improves oxygenation $^{76}$. In patients with acute respiratory distress syndrome, the prone position increases arterial $\mathrm{PO}_{2}$. Alterations in ventilation-perfusion inequality have been suggested as the main reason for improved oxygenation in these body positions $^{77}$.

\section{Percussion and vibration}

Manual or mechanical percussion and vibration are based on the assumption that the oscillatory forces are transmitted to the bronchi. Although such oscillations are observed during bronchoscopy in the central airways, it is believed that absorption of the forces by air and by the lung parenchyma prevents transmission to smaller and intermediate airways. This probably explains the lack of additional effect on mucus transport from adding chest percussion and vibration to breathing retraining, postural drainage and coughing ${ }^{78}$. Another explanation might be the frequency dependence of the effects of vibration and oscillation. The optimal frequency-enhancing mucus transport appears to be around $12-17 \mathrm{~Hz}^{79}$. However, clinical trials have not shown greater efficacy of high frequency oscillation with a more optimal oscillation frequency than in standard physical therapy on patients with chronic bronchitis $^{80}$ and cystic fibrosis in a stable condition ${ }^{81}$ or hospitalized $^{82}$.

\section{Positive expiratory pressure mask breathing and Flutter breathing}

Positive expiratory pressure mask breathing (Figure 7) was introduced to prevent airway collapse and improve collateral ventilation, and thus to enhance mucus transport. Indeed, Falk et al. ${ }^{83}$ showed that the addition of this technique to forced expiration or postural drainage increased the mucus expectoration in cystic fibrosis cases. Other investigators have been unable to show additional short-term effects on mucus transport in cystic fibrosis ${ }^{84}$ or chronic bronchitis ${ }^{85}$. However, it has been demonstrated that positive expiratory pressure therapy is superior to standard treatment in preserving pulmonary function over the long term ${ }^{86}$.

Flutter breathing is the addition of a variable, oscillating expiratory pressure and airflow at the mouth, to facilitate mucus clearance. Although Konstan et al. ${ }^{87}$ observed a fivefold increase in expectorated mucus using this method in patients with cystic fibrosis, in comparison with coughing or postural drainage, other authors have been unable to find differences in expectoration ${ }^{88}$. Sputum rheology has been found to become significantly altered during flutter breathing, but without resulting in increased sputum volume ${ }^{88}$. 


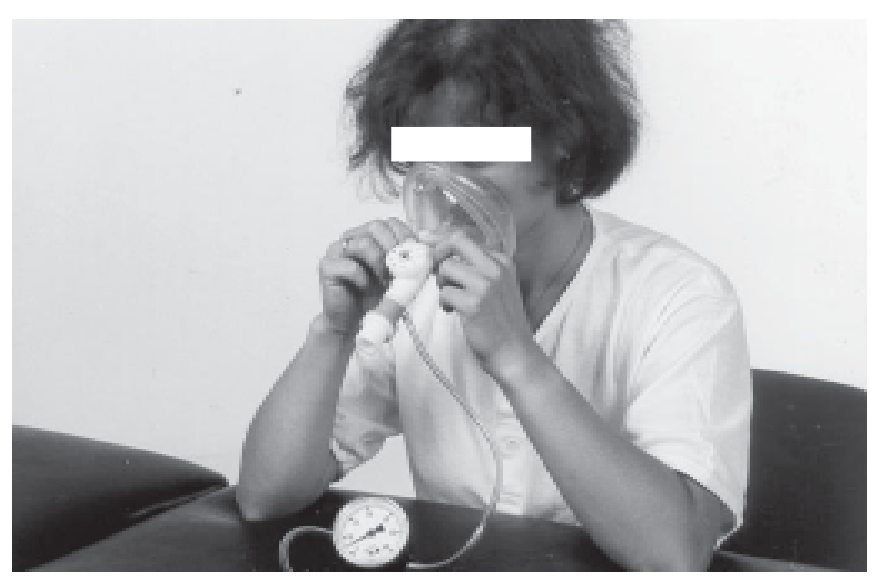

Figure 7. Breathing exercises using positive expiratory pressure (PEP) mask on a patient with cystic fibrosis.

\section{Chest expansion and lung inflation}

Mechanically ventilated patients are often unable to perform forced expiratory maneuvers effectively, due to unconsciousness. Manual hyperinflation combined with chest wall compression during expiration ("bag squeezing”, Figure 8 ) is frequently applied in clinical practice, and this improves oxygenation and lung compliance, and facilitates secretion removal $^{89-91}$. Potential detrimental cardiovascular effects must be taken in consideration when applying manual hyperinflation ${ }^{92}$. Its effectiveness in preventing pulmonary complications and pneumonia has been questioned, but recent data provide some evidence that physical therapy may indeed add to the prevention of ventilator-associated pneumonia ${ }^{93}$.

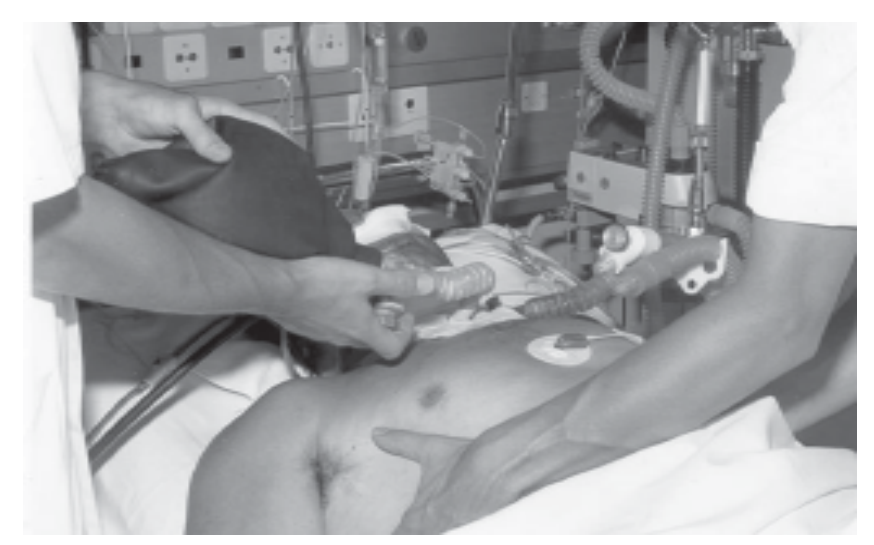

Figure 8. Manual hyperinflation and chest wall compression in a ventilated patient.

Postoperative pulmonary complications following thoracic and abdominal surgery remain a major cause of morbidity and mortality. Prolonged hospitalization and intensive care stay may result. Early mobilization is very effective for preventing pulmonary complications. Evidence for the effectiveness of physical therapy in preventing postoperative pulmonary complications following abdominal surgery is provided by randomized controlled trials ${ }^{94,95}$. In addition, absence of preoperative physical therapy has been found to be an independent factor associated with higher risk of postoperative pulmonary complications in patients with lung resection ${ }^{96}$.

In addition to deep breathing exercises, coughing and early mobilization, incentive spirometry (IS) also promotes reductions in pulmonary complications. Following abdominal surgery, Hall et al. ${ }^{97}$ concluded that incentive spirometry was as effective as chest physical therapy in both low and high-risk patients. Incentive spirometry has not been shown to be of additional value after major abdominal, lung and cardiac surgery ${ }^{98,99}$. In thoracic surgery for lung or esophageal resection, incentive spirometry has been shown to have no additional effect on pulmonary function recovery, pulmonary complications or hospital stay ${ }^{100}$.

\section{CONCLUSION}

Physical therapy is involved in the non-medical treatment of patients with acute and chronic respiratory disease. In addition to its traditional role in treating airflow obstruction and mucus retention, other aspects of respiratory disorders such as ventilatory pump dysfunction, dyspnea, impaired exercise performance and quality of life are also targets for physical therapy interventions. Exercise training, peripheral and respiratory muscle training, airway clearance techniques and lung expansion in spontaneous breathing patients (lung expansion maneuvers, huffing and assisted coughing) and in mechanically ventilated patients (bagsqueezing), and breathing retraining (pused lips breathing, active expiration) have been shown effective in selected patients with disorders affecting the respiratory system. Assessment of patients is critical to identify patient characteristics that allow appropriate selection of treatment modalities providing optimal effectiveness and efficacy.

\section{REFERENCES}

1. Gosselink R, Troosters T, Decramer M. Peripheral muscle weakness contributes to exercise limitation in COPD. Am J Respir Crit Care Med. 1996; (153): 976-80.

2. Saey D, Debigare R, Leblanc P, Mador MJ, Cote CH, Jobin J, Maltais F. Contractile leg fatigue after cycle exercise: a factor limiting exercise in patients with chronic obstructive pulmonary disease. Am J Respir Crit Care Med. 2003; (168): 425-30. 
3. Lacasse, Y, Brosseau L, Milne S, Martin S, Wong E, Guyatt GH, Goldstein RS. Pulmonary rehabilitation for chronic obstructive pulmonary disease. Cochrane Database Syst Rev. [CD-ROM] 2002.

4. Troosters T, Casaburi R, Gosselink R, Decramer M. Pulmonary rehabilitation in chronic obstructive pulmonary disease. Am J Respir Crit Care Med. 2005; (172): 19-38.

5. Vogiatzis I, Nanas S, Roussos C. Interval training as an alternative modality to continuous exercise in patients with COPD. Eur Respir J. 2002; 19.

6. Spruit M, Gosselink R, Troosters T, De Paepe K, Decramer M. Resistance vs endurance training in patients with COPD and peripheral muscle weakness. Eur Respir J. 2002; (19): 1072-78.

7. Simpson K, Killian KJ, McCartney N, Stubbing DG, Jones NL. Randomised controlled trial of weightlifting exercise in patients with chronic airflow limitation. Thorax. 1992; (47): 70-5.

8. Ortega F, Toral J, Cejudo P, Villagomez R, Sanchez H, Castillo J, Montemayor T. Comparison of effects of strength and endurance training in patients with chronic obstructive pulmonary disease. Am J Respir Crit Care Med. 2002; (166): 669-74.

9. Neder JA, Sword D, Ward SA, Mackay E, Cochrane LM, Clark CJ. Home based neuromuscular electrical stimulation as a new rehabilitative strategy for severely disabled patients with chronic obstructive pulmonary disease (COPD). Thorax. 2002; (57): 333-37.

10. Allen C, Glasziou P, Del Mar C. Bed rest: a potentially harmful treatment needing more careful evaluation. Lancet. 1999; (354): 1229-33.

11. Griffiths RD, Palmer A, Helliwell T, Maclennan P, Macmillan RR. Effect of passive stretching on the wasting of muscle in the critically ill. Nutrition.1995; (11): 428-32.

12. Zanotti E, Felicetti G, Maini M, Fracchia C. Peripheral muscle strength training in bed-bound patients with COPD receiving mechanical ventilation:effect of electrical stimulation. Chest. 2003; (124): 292-96.

13. Nava S. Rehabilitation of patients admitted to a respiratory intensive care unit. Arch Phys Med Rehabil. 1998;(79):849-54.

14. Meek P, Schwartzstein R, Adams L, Altose MD, Breslin EH, Carrieri-Kohlman V, et al. Dyspnea mechanisms, assessment, and management: a consensus statement. Am J Respir Crit Care Med. 1999;(159):321-40.

15. O’Donnell DE. Assessment and management of dyspnea in chronic obstructive pulmonary disease. In Similowski T, Whitelaw WA, Derenne JP, editors. Clinical management of chronic obstructive pulmonary disease. New York: Marcel Dekker; 2002. p.113-70.

16. Gosselink R. Breathing techniques in patients with chronic obstructive pulmonary disease (COPD). Chron Respir Dis. 2004;(01):163-72.

17. Renfroe KL. Effect of progressive relaxation on dyspnea and state of anxiety in patients with chronic obstructive pulmonary disease. Heart Lung. 1988; (17): 408-13.

18. Gift AG, Moore T, Soeken K. Relaxation to reduce dyspnea and anxiety in COPD patients. Nurs Res. 1992; (41): 242-46.
19. Kolaczkowski W, Taylor R, Hoffstein V. Improvement in oxygen saturation after chest physiotherapy in patients with emphysema. Physiotherapy. 1989; (41): 18-23.

20. Breslin EH, The pattern of respiratory muscle recruitment during pursed-lips breathing in COPD. Chest. 1992; (101): 75-8.

21. Ingram RH, Schilder DP. Effect of pursed lips breathing on the pulmonary pressure-flow relationship in obstructive lung disease. Am Rev Respir Dis. 1967; (96): 381-88.

22. Mueller RE, Petty TL, Filley GF. Ventilation and arterial blood gas changes induced by pursed lips breathing. J Appl Physiol. 1970; (28): 784-89.

23. Garrod R, Dallimore K, Cook J, Davies V, Quade K. An evaluation of the acute impact of pursed lips breathing on walking distance in nonspontaneous pursed lips breathing chronic obstructive pulmonary disease patients. Chron Respir Dis. 2005; (2): 67-72.

24. Ninane V, Rypens F, Yernault JC, De Troyer A. Abdominal muscle use during breathing in patients with chronic airflow obstruction. Am Rev Respir Dis. 1992; (146): 16-21.

25. Casciari RJ, Fairshter RD, Harrison A, Morrison JT, Blackburn C, Wilson AF. Effects of breathing retraining in patients with chronic obstructive pulmonary disease. Chest. 1981; (79): 3938.

26. Sharp JT, Druz WS, Moisan T, Foster J, Machnach W. Postural relief of dyspnea in severe chronic obstructive pulmonary disease. Am Rev Respir Dis. 1980; (122): 201-11.

27. Banzett R, Topulos G, Leith DE, Natios C. Bracing arms increases the capacity for sustained hyperpnea. Am Rev Respir Dis. 1983; (133): 106-9.

28. Goldman JM, Rose LS, Williams SJ, Silver JR, Denison DM. Effect of abdominal binders on breathing in tetraplegic patients. Thorax. 1986; (41): 940-5.

29. Estenne M, Van Muylem A, Gorini M, Kinnear W, Heilporn A, Troyer A de. Effects of abdominal strapping on forced expiration in tetraplegic patients. Am J Respir Crit Care Med. 1998; (157): 95-8.

30. Levine S, Kaiser L, Leferovich J, Tikunov B. Cellular adaptations in the diaphragm in chronic obstructive pulmonary disease. $\mathrm{N}$ Engl J Med. 1997; (337): 1799-1806.

31. Scherer TA., Spengler C, Owassapian D, Imhof E, Boutellier U. Respiratory muscle endurance training in chronic obstructive pulmonary disease: impact on exercise capacity, dyspnea, and quality of life. Am J Respir Crit Care Med. 2000; (162): 170914.

32. Lotters F, B. Van Tol B, Kwakkel G, Gosselink R. Effects of controlled inspiratory muscle training in patients with COPD: a meta-analysis. Eur Respir J. 2002; (20): 570-6.

33. Ramirez-Sarmiento A, Orozco-Levi M, Guell R, Barreiro E, Hernandez $N$, Mota $S$, et al. Inspiratory muscle training in patients with chronic obstructive pulmonary disease: structural adaptation and physiologic outcomes. Am J Respir Crit Care Med. 2002: 1491-7.

34. Lisboa C, Villafranca C, Leiva A, Cruz E, Pertuze J, Borzone G. Inspiratory muscle training in chronic airflow limitation: effect on exercise performance. Eur Respir J. 1997; (10): 537-42. 
35. Heijdra YF, Dekhuijzen PNR, Herwaarden CLA van, Folgering HTM. Nocturnal saturation improves by target-flow inspiratory muscle training in patients with COPD. Am J Respir Crit Care Med. 1996; (153): 260-5.

36. Dekhuijzen PNR, Folgering HTM, Herwaarden CLA van. Target-flow inspiratory muscle training during pulmonary rehabilitation in patients with COPD. Chest. 1991; (99): 128-33.

37. Wanke T, Formanek D, Lahrmann H, Brath H, Wild M, Wagner C, Zwick $\mathrm{H}$. The effects of combined inspiratory muscle and cycle ergometer training on exercise performance in patients with COPD. Eur Respir J. 1994; (7): 2205-11.

38. Villafranca C, Borzone G, Leiva A, Lisboa C. Effect of inspiratory muscle training with intermediate load on inspiratory power output in COPD. Eur Respir J. 1998; (11): 28-33.

39. Uijl SG, Houtman S, Folgering HT, Hopman MT. Training of the respiratory muscles in individuals with tetraplegia. Paraplegia. 1999; (37): 575-9.

40. Liauw MY, Lin MC, Cheng PT, Wong MK, Tang FT. Resistive inspiratory muscle training: its effectiveness in patients with acute complete cervical cord injury. Arch Phys Med Rehabil. 2000;(81): 752-6.

41. Van Houtte S, Vanlandewijck Y, Gosselink R. Respiratory muscle training in persons with spinal cord injury: a systematic review. Respir Med. 2006.

42. Wanke T, Toifl K, Merkle M, Formanek D, Lahrmann H, Zwick H. Inspiratory muscle training in patients with Duchenne muscular dystrophy. Chest. 1994; (105): 475-82.

43. Gosselink R, Kovacs L, Ketelaer P, Carton H, Decramer, M. Respiratory muscle weakness and respiratory muscle training in severely disabled multiple sclerosis patients. Arch Phys Med Rehabil. 2000; (81): 747-51.

44. Sprague SS, Hopkins PD. Use of inspiratory strength training to wean six patients who were ventilator-dependent. Phys Ther. 2003; (83): 171-81.

45. Martin AD, Davenport PD, Franceschi AC, Harman E. Use of inspiratory muscle strength training to facilitate ventilator weaning: a series of 10 consecutive patients. Chest. 2002; (122): 192-6.

46. Holliday JE, Hyers TM. The reduction of weaning time from mechanical ventilation using tidal volume and relaxation biofeedback. Am Rev Respir Dis. 1990; (141): 1214-20.

47. Sharp JT, Danon J, Druz WS, Goldberg NB, Fishman H, Machnach W. Respiratory muscle function in patients with chronic obstructive pulmonary disease: its relationship to disability and to respiratory therapy. Am Rev Respir Dis. 1974; (110): 154-68.

48. Sharp JT, Goldberg NM, Druz WS, Fishman H, Danon J. Thoracoabdominal motion in COPD. Am Rev Respir Dis. 1977; (115): 47-56.

49. Gandevia SC, Leeper JB, McKenzie DK, De Troyer A. Discharge frequencies of parasternal intercostal and scalene motor units during breathing in normal and COPD subjects. Am J Respir Crit Care Med. 1996; (153): 622-8.

50. De Troyer A, Leeper JB, McKenzie DK, Gandevia SC. Neural drive to the diaphragm in patients with severe COPD. Am J Respir Crit Care Med. 1997; (155): 1335-40.
51. Sinderby C, Beck J, Spahija JA, Weinberg J, Grassino A. Voluntary activation of the diaphragm in health and disease. $\mathrm{J}$ Appl Physiol. 1998; (850): 2146-58.

52. Breslin GH, Garoutte BC, Celli BR. Correlations between dyspnea, diaphragm, and sternomastoid recruitment during inspiratory resistance breathing. Chest. 1990; (98): 298-302.

53. Sackner MA, Gonzalez HF, Jenouri G, Rodriguez M. Effects of abdominal and thoracic breathing on breathing pattern components in normal subjects and in patients with COPD. Am Rev Respir Dis. 1984; (130): 584-7.

54. Grimby G, Oxhoj H, Bake B. Effects of abdominal breathing on distribution of ventilation in obstructive lung disease. Clin Sci Mol Med. 1975; (48): 193-9.

55. Gosselink RAAM, Wagenaar RC, Sargeant AJ, Rijswijk H, Decramer MLA. Diaphragmatic breathing reduces efficiency of breathing in chronic obstructive pulmonary disease. Am J Respir Crit Care Med. 1995; (151): 1136-42.

56. Casaburi R, Porszasz J, Burns MR, Chang RSY, Cooper CB. Physiologic benefits of exercise training in rehabilitation of patients with severe chronic obstructive pulmonary disease. Am J Respir Crit Care Med. 1997; (155): 1541-51.

57. Vestbo J, Prescott E, Lange P. Association of chronic mucus hypersecretion with $\mathrm{FEV}_{1}$ decline and chronic obstructive pulmonary disease morbidity. Am J Respir Crit Care Med. 1996; (153): 1530-35.

58. Lieberman SL, Shefner JM, Young RR. Neurological disorders affecting respiration. In: Roussos C, editor. The Thorax. Part C: Disease. $2^{\mathrm{a}}$ ed. New York: Marcel Dekker; 1995. p. 2135-75.

59. Houtmeyers E, Gosselink R, Gayan-Ramirez G, Decramer M. Effects of drugs on mucus clearance. Eur Respir J. 1999; (14): 452-67.

60. Houtmeyers E, Gosselink R, Gayan-Ramirez G, Decramer M. Regulation of mucociliary clearance in health and disease. Eur Respir J. 1999; (13): 1177-88.

61. Thomas J, Cook DJ, Brooks D. Chest physical therapy management of patients with cystic fibrosis. a meta-analysis. Am J Respir Crit Care Med. 1995; (151): 846-50.

62. Jones AP, Rowe BH. Bronchopulmonary hygiene physical therapy for chronic obstructive pulmonary disease and bronchiectasis. The Cochrane Library. 2000: 1-12.

63. Clarke SW, Jones JG, Oliver DR. Resistance to two-phase gasliquid flow in airways. J Appl Physiol. 1970; (29): 464-71.

64. Bennett WD, Zeman KL. Effect of enhanced supramaximal flows on cough clearance. J Appl Physiol. 1994; (77): 1577-83.

65. Hasani A, Pavia D, Agnew JE, Clarke SW. Regional lung clearance during cough and forced expiration technique (FET): effects of flow and viscoelasticity. Thorax. 1994; (49): 557-561.

66. Hasani A, Pavia D, Agnew JE, Clarke SW. Regional mucus transport following unproductive cough and forced expiration technique in patients with airways obstruction. Chest. 1994; (105): 1420-5.

67. Sivasothy P, Brown L, Smith IE, Shneerson JM. Effect of manually assisted cough and mechanical insufflation on cough flow of normal subjects, patients with chronic obstructive pulmonary disease (COPD), and patients with respiratory muscle weakness. Thorax. 2001; (56): 438-44. 
68. Bach JR. Mechanical insufflation-exsufflation. Comparison with peak expiratory flows with manually assisted and unassisted coughing techniques. Chest. 1993; (104): 1553-62.

69. Warren VC. Glossopharyngeal and neck accessory muscle breathing in a young adult with C2 complete tetraplegia resulting in ventilator dependency. Phys Ther. 2002; (82): 590-600.

70. Wolff RK, Dolovich MB, Obminski G, Newhouse MT. Effects of exercise and eucapnic hyperventilation on bronchial clearance in man. J Appl Physiol. 1977; (43): 46-50.

71. Oldenburg FA, Dolovich MB, Montgomery JM, Newhouse MT. Effects of postural drainage, exercise and cough on mucus clearance in chronic bronchitis. Am Rev Respir Dis. 1979; (120): 739-45.

72. Salh W, Bilton D, Dodd M, Webb AK. Effect of exercise and physiotherapy in aiding sputum expectoration in adults with cystic fibrosis. Thorax. 1989; (44): 1006-8.

73. Baldwin DR, Hill AL, Peckham DG, Knox AJ. Effect of addition of exercise to chest physiotherapy on sputum expectoration and lung function in adults with cystic fibrosis. Respir Med. 1994; (88): 49-53.

74. Rossman CM, Waldes R, Sampson D, Newhouse MT. Effect of chest physiotherapy on the removal of mucus in patients with cystic fibrosis. Am Rev Respir Dis. 1982; (126): 131-5.

75. Sutton PP, Parker RA, Webber BA, Newman SP, Garland N, Lopez-Vidriero MT, et al. Assessment of the forced expiration technique, postural drainage and directed coughing in chest physiotherapy. Eur J Respir Dis. 1983; (64): 62-8.

76. Gillespie DJ, Rehder K. Body position and ventilation-perfusion relationships in unilateral pulmonary disease. Chest. 1987; (91): 75-9.

77. Lamm WJE, Graham MM, Albert RK. Mechanism by which the prone position improves oxygenation in acute lung injury. Am J Respir Crit Care Med. 1994; (150): 184-93.

78. Van der Schans CP, Piers DA, Postma DS. Effect of manual percussion on tracheobronchial clearance in patients with chronic airflow obstruction and excessive tracheobronchial secretion. Thorax. 1986; (41): 448-52.

79. King M, Philips DM, Gross D, Vartian V, Chang HK, Zidulka A. Enhanced tracheal mucus clearance with high frequency chest wall compression. Am Rev Respir Dis. 1983; (128): 511-5.

80. Van Hengstum M, Festen J, Beurskens C, Hankel M, Van den Broek W, Corstens F. No effect of oral high frequency oscillation combined with forced expiration manoeuvres on tracheobronchial clearance in chronic bronchitis. Eur Respir J. 1990; ( 3): 14-18.

81. Natale JE, Pfeifle J, Homnick DN. Comparison of intrapulmonary percussive ventilation and chest physiotherapy. A pilot study in patients with cystic fibrosis. Chest. 1994; (105): 1789-93.

82. Arens R, Gozal D, Omlin KJ, Veja J, Boyd KP, Keens TG, Woo MS. Comparison of high frequency chest compression and conventional chest physiotherapy in hospitalized patients with cystic fibrosis. Am J Respir Crit Care Med. 1994; (150): 11547.

83. Falk M, Kelstrup M, Andersen JB, Kinoshita T, Falk P, Stovring $\mathrm{S}$, et al. Improving the ketchup bottle method with positive expiratory pressure (PEP), in cystic fibrosis. Eur J Respir Dis. 1984; (65): 423-32.
84. Lannefors L, Wollmer P. Mucus clearance with three chest physiotherapy regimes in cystic fibrosis: a comparison between postural drainage, PEP and physical exercise. Eur Respir J. 1992; (5): 748-53.

85. Van Hengstum M, Festen J, Beurskens C, Hankel M, Beekman F, Corstens F. Effect of positive expiratory pressure mask physiotherapy (PEP) versus forced expiration technique (FET/ $\mathrm{PD}$ ) on regional lung clearance in chronic bronchitics. Eur Respir J. 1991; (4): 651-4.

86. McIlwaine PM, Wong LT, Peacock D, Davidson AGF. Longterm comparative trial of conventional postural drainage and percussion versus positive expiratory pressure therapy in the treatment of cystic fibrosis. J Pediatr. 1997; (131): 570-4.

87. Konstan MW, Stern RC, Doershuk CF. Efficacy of the Flutter device for airway mucus clearance in patients with cystic fibrosis. J Pediatr. 1994; (124): 689-93.

88. App EM, Kieselmann R, Reinhardt D, Lindemann H, Dasgupta B, King M, Brand P. Sputum rheology changes in cystic fibrosis lung disease following two different types of physiotherapy: flutter vs autogenic drainage. Chest. 1998; (114): 171-7.

89. Jones AYM, Hutchinson RC, Oh TE. Chest physiotherapy practice in intensive care units in Australia, the UK and Hong Kong. Physioth Theory and Pract. 1992; (8): 39-47.

90. Hodgson C, Denehy L, Ntoumenopoulos G, Santamaria J, Carroll S. An investigation of the early effects of manual lung hyperinflation in critically ill patients. Anaesth Intensive Care. 2000; (28): 255-61.

91. Tugrul S, Akinci O, Ozcan PE, Ince S, Esen F, Telci L, et al. Effects of sustained inflation and postinflation positive endexpiratory pressure in acute respiratory distress syndrome: focusing on pulmonary and extrapulmonary forms. Crit Care Med. 2003; (31): 738-44.

92. Singer M, Vermaat J, Hall G, Latter G, Patel M. Hemodynamic effects of manual hyperinflation in critically ill mechanically ventilated patients. Chest. 1994; (106): 1182-7.

93. Ntoumenopoulos G, Presneill JJ, McElholum M, Cade JF. Chest physiotherapy for the prevention of ventilator-associated pneumonia. Intensive Care Med. 2002; (28): 850-56.

94. Fagevik O, Hahn MI, Nordgren S, Lonroth H, Lundholm K. Randomized controlled trial of prophylactic chest physiotherapy in major abdominal surgery. Brit J Surg. 1997; (84): 1535-38.

95. Thomas JA, McIntosh JM. Are incentive spirometry, intermittent positive pressure breathing and deep breathing exercises effective in the prevention of postoperative pulmonary complications after abdominal surgery:a systematic overview and meta-analysis. Phys Ther. 1994; (74): 3-10.

96. Algar FJ, Alvarez A, Salvatierra A, Baamonde C, Aranda JL, Lopez-Pujol FJ. Predicting pulmonary complications after pneumonectomy for lung cancer. Eur J Cardiothorac Surg. 2003; (23): 201-8.

97. Hall JC, Tarala R, Harris J, Tapper J, Christiansen K Incentive spirometry versus routine chest physiotherapy for prevention of pulmonary complications after abdominal surgery [see comments]. Lancet. 1991; (337): 953-56. 
98. Crowe JM, Bradley CA. The effectiveness of incentive spirometry with physical therapy for high-risk patients after coronary artery bypass surgery. Phys Ther. 1997; (77): 260-68.

99. Overend TJ, Anderson CM, Lucy SD, Bhatia C, Jonsson BI, Timmermans C. The effect of incentive spirometry on postoperative pulmonary complications: a systematic review. Chest. 2001; (120): 971-78.
100.Gosselink R, Schrever K, De Leyn P, Troosters T, Lerut A, Decramer $M$. Recovery after thoracic surgery is not accelerated with incentive spirometry. Crit Care Med.2000; (28): 679-83. 